\title{
The anti-inflammatory effects of Indonesian and Japanese bitter melon (Momordica charantia L.) fruit extracts on interleukin-1 $\beta$ - treated hepatocytes
}

\author{
Dinia Rizqi Dwijayanti1,2, Tetsuya Okuyama1, Tadayoshi Okumura ${ }^{3,4}$, Yukinobu \\ Ikeya $^{5}$ and Mikio Nishizawa ${ }^{1}$
}

\begin{abstract}
${ }^{1}$ Department of Biomedical Sciences, College of Life Sciences, Ritsumeikan University, Kusatsu, Shiga, Japan; ${ }^{2}$ Graduate School of Life Sciences, Ritsumeikan University, Kusatsu, Shiga, Japan; ${ }^{3}$ Research Organization of Science and Technology, Ritsumeikan University, Kusatsu, Shiga, Japan; ${ }^{4}$ Department of Surgery, Kansai Medical University, Hirakata, Osaka, Japan; ${ }^{5}$ Department of Pharmacy Educational Assist Center, Daiich University of Pharmacy, Fukuoka, Japan
\end{abstract}

Corresponding author: Mikio Nishizawa, M.D., Ph.D., Department of Biomedical Sciences, College of Life Sciences, Ritsumeikan University, 1-1-1 Nojihigashi, Kusatsu, Shiga 525-8577, Japan

Submission date: September $26^{\text {th }}$, 2018, Acceptance Date: January $28^{\text {th }}$, 2019, Publication Date: January $31^{\text {st }}, 2019$

Citation: Dwijayanti D.R., Okuyama T., Okumura T., Ikeya Y., Nishizawa M. The antiinflammatory effects of Indonesian and Japanese bitter melon (Momordica charantia L.) fruit extracts on interleukin-1 $\beta$-treated hepatocytes. Functional Foods in Health and Disease 2019; 9(1): 16-33. DOI: https://doi.org/10.31989/ffhd.v9i1.560

\footnotetext{
ABSTRACT

Background: Bitter melon, Momordica charantia L. (Cucurbitaceae), grows in tropical to temperate regions in Asia, including Indonesia and Japan. Bitter melon contains triterpenoids, steroidal glycosides, flavonoids, and alkaloids. The green immature fruit of bitter melon is a popular vegetable in Indonesia and Japan and has been used as a traditional Indonesian medicine $(\mathrm{Jamu})$ to treat microbial infections and diabetes mellitus. However, there are currently few reports about the pharmacological effects of the constituents of bitter melon.
} 
Objective: To compare the effects of Indonesian and Japanese bitter melon, the production of pro-inflammatory mediators, such as nitric oxide (NO) and pro-inflammatory cytokines, was monitored.

Methods: Immature fruits of bitter melons collected from Indonesia and Japan were lyophilized and extracted with methanol. The resultant extracts were fractionated by hydrophobicity into ethyl acetate-soluble (A), n-butanol-soluble (B), and water-soluble (C) fractions. Primary cultured hepatocytes prepared from rat liver were treated with interleukin$1 \beta$ (IL-1 $\beta$ ) and each extract or fraction. Nitrite in the medium was measured, and the halfmaximal inhibitory concentration ( $\mathrm{IC}_{50}$ ) value was determined. Lactate dehydrogenase activity in the medium was measured to monitor cytotoxicity. The expression of inducible nitric oxide synthase (iNOS) was detected by western blot analysis. The mRNA levels were measured by reverse transcription-polymerase chain reaction.

Results: Indonesian and Japanese bitter melon extracts (BMEs) suppressed NO production by IL-1 $\beta$-treated hepatocytes without showing cytotoxicity. The $\mathrm{IC}_{50}$ values of the BMEs were 86 $\mu \mathrm{g} / \mathrm{mL}$ (Indonesian) and $171 \mu \mathrm{g} / \mathrm{mL}$ (Japanese). Both BMEs suppressed iNOS protein expression. Fractions A and B of both BMEs suppressed NO production. The $\mathrm{IC}_{50}$ values of the Indonesian BME fractions A and B were comparable to those of Japanese BME. Fraction A of both BMEs decreased the levels of iNOS protein and mRNA, as well as those of proinflammatory cytokine mRNAs. Fraction $\mathrm{C}$ of both BMEs did not affect NO production.

Conclusion: The ethyl acetate-soluble fraction (A) of Indonesian and Japanese BMEs exhibited a comparable ability to suppress the induction of the iNOS and pro-inflammatory cytokine genes. These data suggest that hydrophobic constituents in fraction A, such as cucurbitane-type triterpenoids, may be responsible for the observed anti-inflammatory effects of bitter melon from Indonesia and Japan.

Keywords: Momordica charantia, nitric oxide, inflammation, Jamu, Goya.

\section{INTRODUCTION}

Bitter melon (Momordica charantia L.), a member of family Cucurbitaceae, is a woodbine that grows in tropical to temperate regions in Asia, including Indonesia and Japan. This plant is known as Pare (Indonesia) and Tsurureishi or Goya (Japan). This plant's immature, green fruit is a common vegetable in Indonesia and Japan (Figure 1). Bitter melon has also been used as a 
traditional medicine in Indonesia to treat microbial infections and diabetes mellitus and is known as Jати. Bitter melon contains many constituents: cucurbitane-type triterpenoids (e.g., momordicins, charantin, kuguacins, and karavilagenins) [1-4], phenolic compounds (e.g., gallic acid, tannic acid, caffeic acid, and p-coumaric acid), flavonoids (e.g., catechin and epicatechin) [5-7], cucurbitane-type triterpene glycosides (e.g., momordicosides, karavilosides, and goyaglycosides) [8,9], steroidal glycosides, alkaloids, and polysaccharides.

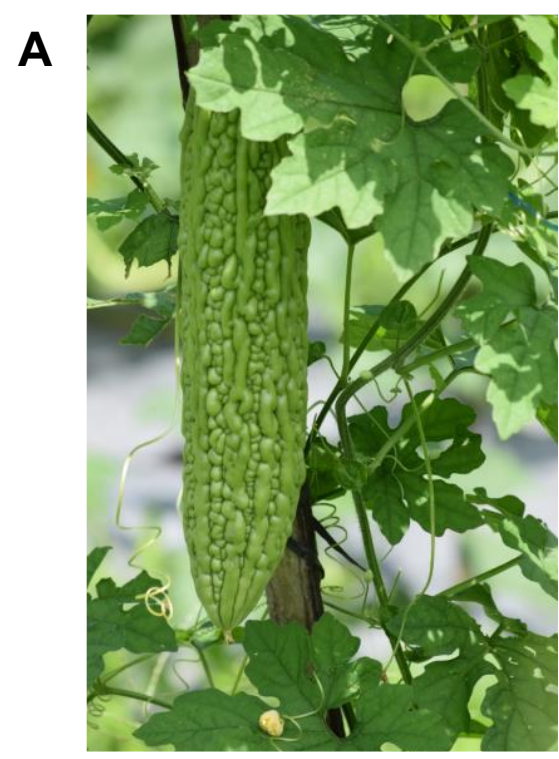

B

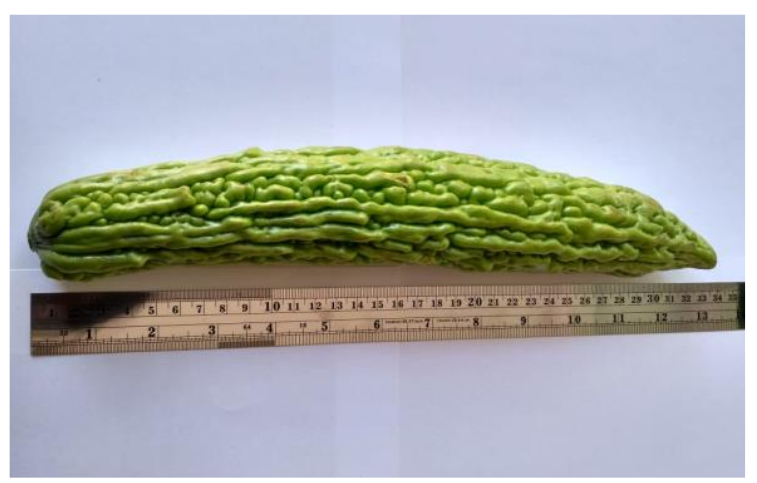

Figure 1. Indonesian bitter melon. An immature fruit of Indonesian bitter melon (A) with scale in $\mathrm{cm}$ and $\mathrm{mm}(\mathbf{B})$. The appearance of Japanese bitter melon is almost the same as the Indonesian one.

There are several reports investigating the efficacy of bitter melon for treating obesity, dyslipidemia, liver disease, and diabetes mellitus. A bitter melon extract was demonstrated to reduce fat deposition and body weight gain, which are early signs of obesity $[10,11]$. A bitter melon extract was previously observed to attenuate high lipid levels in diabetic rats fed a highfat diet in a rat model of dyslipidemia [11]. Rats fed a bitter melon powder with cholesterol exhibited decreased hepatic total cholesterol and triglyceride levels [12]. The hepatoprotective activity of bitter melon extract may be related to its antioxidant ability to scavenge free radicals and reduce inflammation caused by noxious stimuli in the liver. Recent studies demonstrated that bitter melon can decrease oxidative stress in the liver by increasing the antioxidant activity of super oxide dismutase, glutathione peroxidase, and catalase [13, 14]. Furthermore, there 
have been reports about the antidiabetic and antihyperglycemic effects of bitter melon in several animal models [15-17].

Nitric oxide (NO) is a pro-inflammatory mediator that plays crucial roles in signal transduction in response to inflammation, vasodilation, and neurotransmission [18]. NO kills bacteria and inhibits viral growth. However, NO causes tissue damage when it is synthesized in excess under a pathophysiological condition [19]. The production of NO in the cell is catalyzed by inducible nitric oxide synthase (iNOS), which can be induced in several cell types, including hepatocytes $[20,21]$. The production of NO and the expression of $i N O S$ gene in rat hepatocytes is induced by the pro-inflammatory cytokine interleukin (IL)-1 $\beta$ [22].

Because there has not been significant study on the anti-inflammatory effects of bitter melon, we obtained extracts of Indonesian and Japanese bitter melons, fractionated them, and compared the effects of these fractions by monitoring NO production in hepatocytes. Furthermore, we investigated the effect of bitter melon extracts and their fractions on the expression of genes encoding iNOS, pro-inflammatory cytokines, and chemokines.

\section{MATERIALS AND METHODS}

\section{Plant materials and extraction}

The immature fruits of bitter melon collected in Malang, East Java, Indonesia, and in Okinawa, Japan were purchased. After removing the seeds, the fruit was freeze-dried (kindly performed by Amino Up Co., Ltd., Sapporo, Japan). Voucher specimens of the dried fruit were deposited in the Ritsumeikan Herbarium of Pharmacognosy, Ritsumeikan University, under the code numbers RIN-MC-018 (Indonesia) and RIN-MC-019 (Japan).

The freeze-dried fruits of Indonesian and Japanese melon $(80.07 \mathrm{~g}$ and $33.39 \mathrm{~g})$ were extracted by absolute methanol ( $800 \mathrm{~mL}$ and $700 \mathrm{~mL}$, respectively) under reflux at $60{ }^{\circ} \mathrm{C}$ for 1 h. This procedure was repeated, and the pooled methanol extracts were filtered and evaporated in vacuo. The resulting powder was dissolved in water and used as a bitter melon extract for the subsequent assays. As shown in Figure 2, the extracts were fractionated by hydrophobicity into an ethyl acetate-soluble fraction (A, hydrophobic), an $n$-butanol-soluble fraction (B, amphipathic), and a water-soluble fraction ( $\mathrm{C}$, hydrophilic), according to the previously published method [23]. 


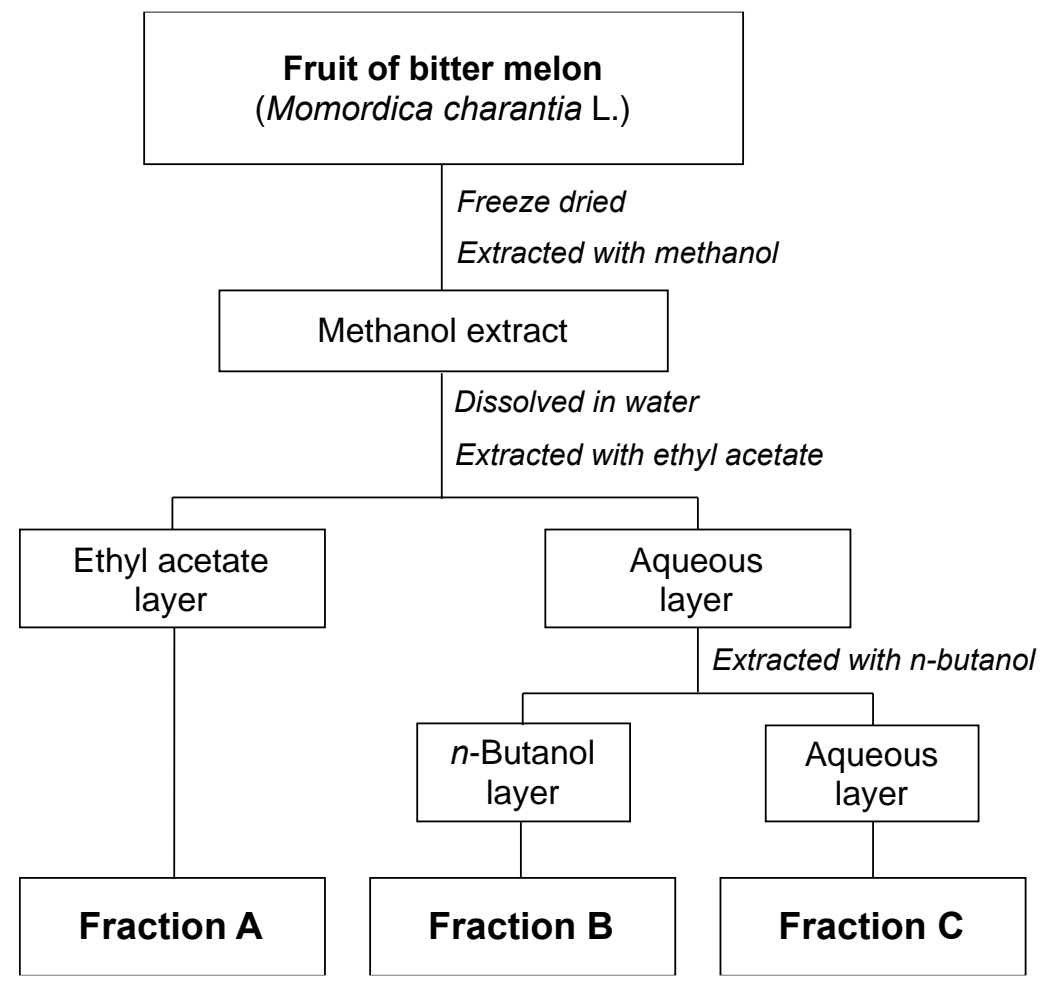

Figure 2. Fractionation of bitter melon extract. A flowchart of the procedures used to prepare three crude fractions from Indonesian and Japanese bitter melon. The freeze-dried fruit of bitter melon was extracted and sequentially fractionated into ethyl acetate-, $n$-butanol, and watersoluble fractions.

\section{Primary cultured rat hepatocytes}

Specific pathogen-free male Wistar rats were purchased from Charles River Laboratories Japan Inc. (Yokohama, Japan), housed at $21-23{ }^{\circ} \mathrm{C}$ under a 12 -h light-dark cycle, with a $\gamma$-rayirradiated CRF-1 diet (Charles River Laboratories Japan Inc.) and water provided ad libitum. The rats were acclimatized for a week. Hepatocytes were isolated from the rat livers by collagenase perfusion, resuspended in Williams' E (WE) medium (Sigma-Aldrich Corp., St. Louis, MO, USA), and seeded at $1.2 \times 10^{6}$ cells per $35-\mathrm{mm}$ diameter dish [24]. The hepatocytes were incubated at $37{ }^{\circ} \mathrm{C}$ overnight and then were treated with $1 \mathrm{nM}$ rat IL-1 $\beta$ and an extract or fraction for $8 \mathrm{~h}$. All the animal care and experimental procedures were carried out in accordance with the guidelines and laws of the Japanese Government and were approved by the Animal Care Committee of Ritsumeikan University, Biwako-Kusatsu Campus.

\section{Determination of NO levels and lactate dehydrogenase (LDH) activity}

The hepatocytes were treated with each extract or fraction in the presence or absence of $1 \mathrm{nM}$ recombinant rat IL- $1 \beta$ for $8 \mathrm{~h}$ at $37^{\circ} \mathrm{C}$. The levels of nitrite (a stable metabolite of NO) in the medium were measured using the Griess method [25]. Briefly, $150 \mu \mathrm{L}$ of the medium or sodium 
nitrite (standard) was mixed with $150 \mu \mathrm{L}$ of the Griess reagent $[0.5 \%$ sulfanilamide, $0.05 \% \mathrm{~N}$ (1-napthyl) ethylenediamine, and $2.5 \%$ phosphoric acid]. After $5 \mathrm{~min}$ at room temperature, the absorbance at $540 \mathrm{~nm}$ was measured. To monitor the cytotoxicity, LDH activity in the medium was measured using a Cytotoxicity LDH Assay Kit-WST (Dojindo Molecular Technologies Inc., Japan). Whole cell extracts were prepared from the hepatocytes by cell lysis using $2 \%$ (w/v) Triton X-100. Unless cytotoxicity was observed, the half-maximal inhibitory concentrations ( $\left.\mathrm{IC}_{50}\right)$ were determined [26].

\section{Western blot analysis}

The hepatocytes were treated with $1 \mathrm{nM} \mathrm{IL}-1 \beta$ and an extract or fraction for $8 \mathrm{~h}$ at $37^{\circ} \mathrm{C}$, after which whole-cell lysates were prepared [27]. Briefly, the hepatocytes were lysed, subjected to sodium dodecyl sulfate-polyacrylamide gel electrophoresis (SDS-PAGE), and electroblotted onto a Sequi-Blot membrane (Bio-Rad, Hercules, CA, USA). Immunostaining was performed using primary antibodies that were raised against rat iNOS (Thermo Fisher Scientific, Waltham, MA, USA) and rat $\beta$-tubulin (Cell Signaling Technology Inc., Danvers, MA, USA), followed by visualization with an Enhanced Chemiluminescence (ECL) Blotting Detection Reagent (GE Healthcare Biosciences Corp., Piscataway, NJ, USA).

\section{Reverse transcription-polymerase chain reaction (RT-PCR)}

The hepatocytes were treated with $1 \mathrm{nM} \mathrm{IL-1} \beta$ and/or an extract fraction for $4 \mathrm{~h}$, after which the total RNA was prepared. The cDNA was reverse-transcribed in a strand-specific manner using an oligo (dT) primer for mRNA and a sense primer for the antisense transcripts (asRNAs) from the $i N O S$ gene (Table 1). PCR was performed with paired primers (Table 1). The levels of each transcript were measured in triplicate by quantitative PCR with a Thermal Cycler Dice Real Time System (Takara Bio Inc.). The obtained values mRNA levels were normalized to the internal control, the elongation factor $1 \alpha(\mathrm{EF})[21]$.

\section{Statistical analysis}

The results presented in the figures are representative of at least three independent experiments that yielded similar results. The values are presented as the means \pm standard deviation (SD). The differences were analyzed using Student's $t$-test. The statistical significance was set at $P$ $<0.05$ and $P<0.01$ 
Table 1. Primers used in this study

\begin{tabular}{llll}
\hline Transcript & Sequence $\left(5^{\prime} \rightarrow 3^{\prime}\right)$ & RT-PCR & Direction \\
\hline iNOS mRNA & CCAACCTGCAGGTCTTCGATG & PCR & Forward \\
& GTCGATGCACAACTGGGTGAAC & PCR & Reverse \\
iNOS asRNA & TGCCCCTCCCCCACATTCTCT & RT & Forward \\
& ACCAGGAGGCGCCATCCCGCTGC & PCR & Forward \\
& ATCTTCATCAAGGAATTATACACGG & PCR & Reverse \\
TNF- $\alpha$ mRNA & TCCCAACAAGGAGGAGAAGTTCC & PCR & Forward \\
& GGCAGCCTTGTCCCTTGAAGAGA & PCR & Reverse \\
IL-6 mRNA & GAGAAAAGAGTTGTGCAATGGCA & PCR & Forward \\
& ATAGGCAAATTCCTGGTTATATCC & PCR & Reverse \\
CCL20 mRNA & CAGCCAGTCAGAAGCAGCAAGCA & PCR & Forward \\
& CTTGGTTCTTAGGCTGAGGAGGT & PCR & Reverse \\
CX3CL1 mRNA & GTACTCTGCTGGCGGGTCAGCAC & PCR & Forward \\
& TCTCGTCTCCAGGATGATGGCGC & PCR & Reverse \\
& TCTGGTTGGAATGGTGACAACATGC & PCR & Forward \\
& CCAGGAAGAGCTTCACTCAAAGCTT & PCR & Reverse \\
\hline
\end{tabular}

RT, reverse transcription; PCR, polymerase chain reaction; iNOS, inducible nitric oxide synthase; asRNA, antisense transcript; TNF- $\alpha$, tumor necrosis factor $\alpha$; IL-6, interleukin 6; CCL20, chemokine C-C motif ligand 20; CX3CL1, chemokine $\mathrm{C}-\mathrm{X}_{3}-\mathrm{C}$ motif ligand 1; EF, elongation factor $1 \alpha$.

\section{RESULTS}

\section{Preparation of extracts from Indonesian and Japanese bitter melon fruit}

To analyze the pharmacological effects of bitter melon extracts, we collected the immature bitter melon fruit from Malang, Indonesia (2.00 kg), and Okinawa, Japan (25.58 kg). Seeds were removed from the fruit and freeze-dried to obtain $108.2 \mathrm{~g}$ (Indonesian) and $1.451 \mathrm{~kg}$ (Japanese) of the dried fruit. The resultant fruit was extracted with methanol and evaporated, with the resulting extracts used in subsequent assays.

\section{Indonesian and Japanese bitter melon extracts suppress $N O$ production in hepatocytes}

We examined the effect of the methanol extracts of the freeze-dried Indonesian and Japanese bitter melon fruits on NO production in IL-1 $\beta$-treated hepatocytes. When Indonesian or Japanese bitter melon extract (BME) was simultaneously added to the medium with IL-1 $\beta$, both dose-dependently suppressed the levels of NO production (Figure 3A). 
To monitor cytotoxicity, we measured the LDH activity in the medium. The LDH activity in the medium was very low, less than 5\% (Figure 3B). These results suggest neither Indonesian nor Japanese BMEs were toxic to the hepatocyte at the concentration indicated. The $\mathrm{IC}_{50}$ values of Indonesian and Japanese BMEs were comparable (Table 2).

A

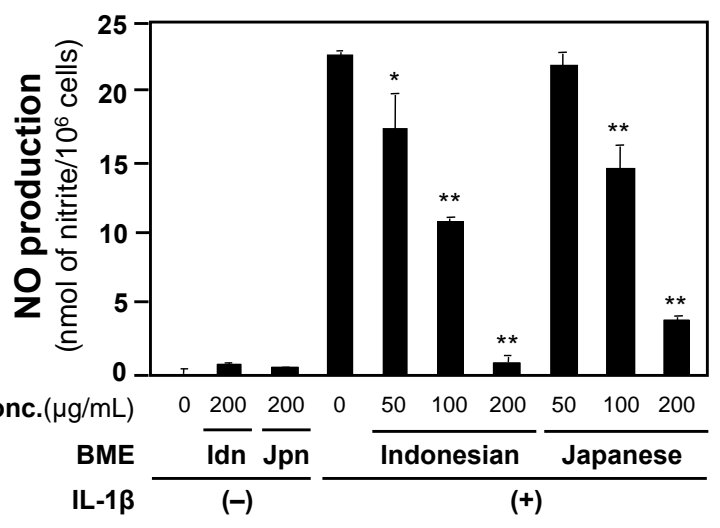

B

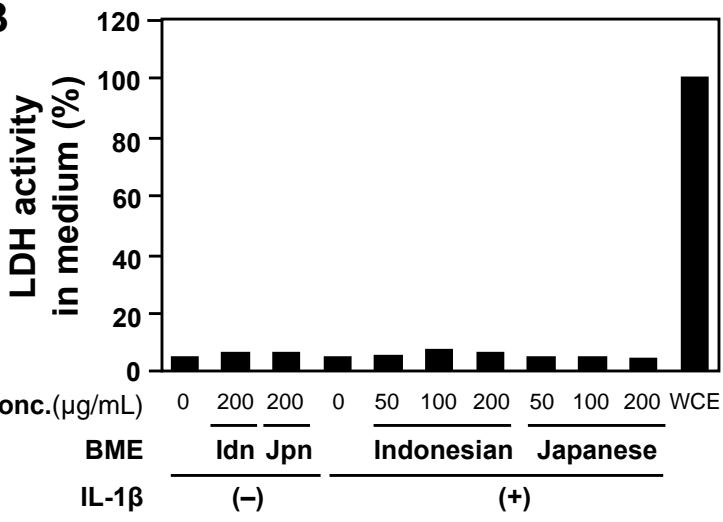

C

\begin{tabular}{|c|c|c|c|c|c|c|c|c|c|c|}
\hline \multirow{3}{*}{$\begin{array}{r}\text { IL-1及 } \\
\text { BME } \\
\text { Conc. }(\mu \mathrm{g} / \mathrm{mL})\end{array}$} & \multicolumn{3}{|c|}{$(-)$} & \multicolumn{7}{|c|}{$(+)$} \\
\hline & & \multirow{2}{*}{$\frac{\text { Idn }}{200}$} & \multirow{2}{*}{$\frac{\text { Jpn }}{200}$} & \multirow[b]{2}{*}{0} & \multicolumn{3}{|c|}{ Indonesian } & \multicolumn{3}{|c|}{ Japanese } \\
\hline & 0 & & & & 50 & 100 & 200 & 50 & 100 & 200 \\
\hline $\begin{array}{r}\text { iNOS } \\
(130 \mathrm{kDa})\end{array}$ & & & & $-\infty$ & - & & & - & $m$ & $+\infty$ \\
\hline $\begin{array}{r}\boldsymbol{\beta} \text {-Tubulin } \\
(55 \mathrm{kDa})\end{array}$ & & & & & & & & & & \\
\hline
\end{tabular}

Figure 3. Indonesian and Japanese bitter melon extracts (BMEs) suppress nitric oxide (NO) production in hepatocytes. (A) The effects of Indonesian (Idn) and Japanese (Jpn) BMEs on the induction of NO production. The hepatocytes were treated with IL-1 $\beta$ and/or Indonesian and Japanese BMEs for $8 \mathrm{~h}$. The NO levels in the medium were measured in triplicate and are shown as a means \pm standard deviation (SD). ${ }^{*} P<0.05$ and ${ }^{* *} P<0.01$ versus IL-1 $\beta$ alone. (B) The LDH activities of the medium of (A). A whole cell extract (WCE) was prepared from the hepatocytes as the positive control of 100\% activity. (C) The effects of Indonesian and Japanese BMEs on the induction of iNOS protein production. The cell extracts from the hepatocytes were resolved using SDS-PAGE and detected with an anti-iNOS or anti- $\beta$-tubulin antibody (internal control).

Next, we investigated the effects of Indonesian and Japanese BMEs on iNOS protein expression. As shown in Figure 3C, western blot analysis indicated that Indonesian and Japanese BMEs dose-dependently decreased the iNOS protein expression in IL- $1 \beta$-treated hepatocytes. These data suggest that Indonesian and Japanese BMEs have a similar activity with respect to the suppression of NO production and iNOS protein expression. 


\section{Fractionation of the bitter melon extracts}

The extracts from the fruit of bitter melon were fractionated into three crude fractions based on hydrophobicity using ethyl acetate (fraction A), $n$-butanol (fraction $\mathrm{B}$ ), and water (fraction $\mathrm{C}$ ). As shown in Table 2, fraction $\mathrm{C}$ was the major fraction in the extracts from Indonesian and Japanese bitter melon. In general, fraction C contains hydrophilic constituents, such as sugars, peptides, and amino acids [23].

\section{Effects of fractions $A$ and B of Indonesian and Japanese BMEs on NO production and iNOS protein expression}

Next, we examined the effects of the fractions of Indonesian and Japanese BMEs on NO production in the presence of IL-1 $\beta$ in rat hepatocytes. Fractions A and B of Indonesian and Japanese BMEs decreased IL-1 $\beta$-induced NO production. In contrast, fraction C from both BMEs did not affect NO production (Figure 4). The LDH activity in the medium did not increase in response to the addition any of the fractions (data not shown), indicating that the fractions did not possess cytotoxicity. As shown in Table 2, fraction A from both the Indonesian and Japanese BMEs exhibited comparable $\mathrm{IC}_{50}$ values.

Table 2. The effect of Indonesian and Japanese bitter melon on nitric oxide (NO) production in hepatocytes.

Fraction

Indonesian bitter melon

Freeze-dried immature fruit

Methanol extract (BME)

Ethyl acetate-soluble fraction (A)

$n$-Butanol-soluble fraction (B)

Water-soluble fraction $(\mathrm{C})$
Weight $(\mathrm{g}) \quad$ Yield $(\%)^{*} \quad \mathrm{IC}_{50}(\mu \mathrm{g} / \mathrm{mL})^{* *}$

80.70

8.02

100

$85.9 \pm 13.4$

1.15

15.8

$56.0 \pm 7.1$

0.70

9.6

$152.5 \pm 28.0$

5.43

74.5

\section{Japanese bitter melon}

Freeze-dried immature fruit

Methanol extract (BME)

5.38

100

$171.2 \pm 13.2$

Ethyl acetate-soluble fraction (A)

0.45

10.0

$57.1 \pm 20.4$

$n$-Butanol-soluble fraction (B)

1.34

29.9

$404.9 \pm 20.0$

Water-soluble fraction $(\mathrm{C})$

2.69

60.1

\footnotetext{
* The sums of fractions of Indonesian and Japanese BMEs were $7.28 \mathrm{~g}$ and $4.48 \mathrm{~g}$, respectively. The sums were assumed as $100 \%$. $^{* *}$ The half-maximal inhibitory concentration of NO production in IL$1 \beta$-treated hepatocytes (mean $\pm \mathrm{SD}$ ). At least three experiments were performed.
} 


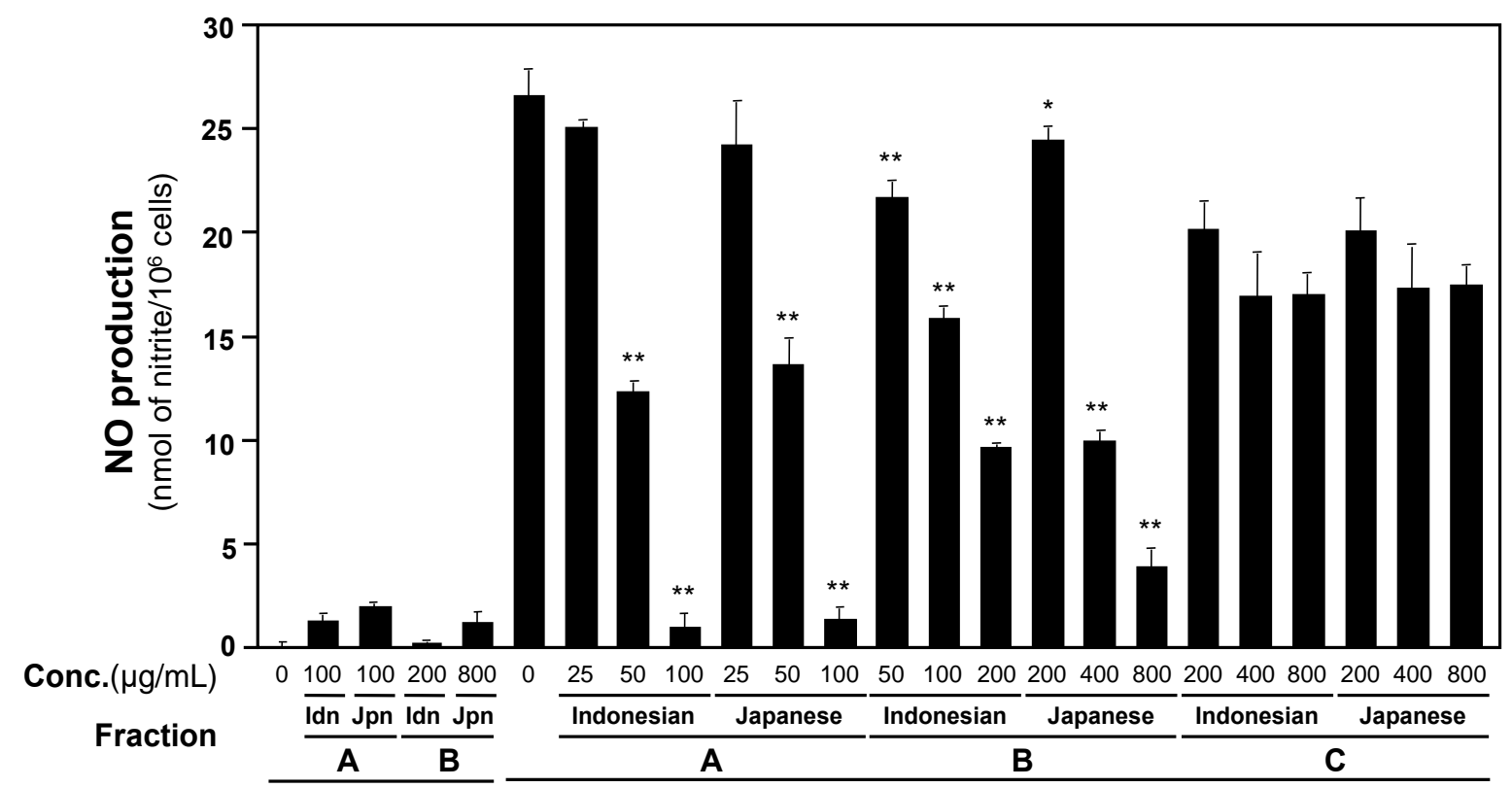

IL-1 $\beta$

$(-)$

$(+)$

Figure 4. Fractions A and B of Indonesian and Japanese bitter melon extracts (BMEs) suppress NO production in hepatocytes. The effects of fractions A and B from Indonesian (Idn) and Japanese (Jpn) BMEs on the induction of NO production. The hepatocytes were treated with IL-1 $\beta$ and/or Indonesian and Japanese BMEs for $8 \mathrm{~h}$ at $37{ }^{\circ} \mathrm{C}$. The NO levels in the medium were measured in triplicate (mean $\pm \mathrm{SD}$ ). ${ }^{*} P<0.05$ and ${ }^{* *} P<0.01$ versus $\mathrm{IL}-1 \beta$ alone.

Fractions A and B of Indonesian and Japanese BMEs also reduced IL-1 $\beta$-induced iNOS protein expression in hepatocytes (Figure 5). Fraction A of Indonesian and Japanese BMEs demonstrated comparable activity in suppressing NO production and iNOS expression.

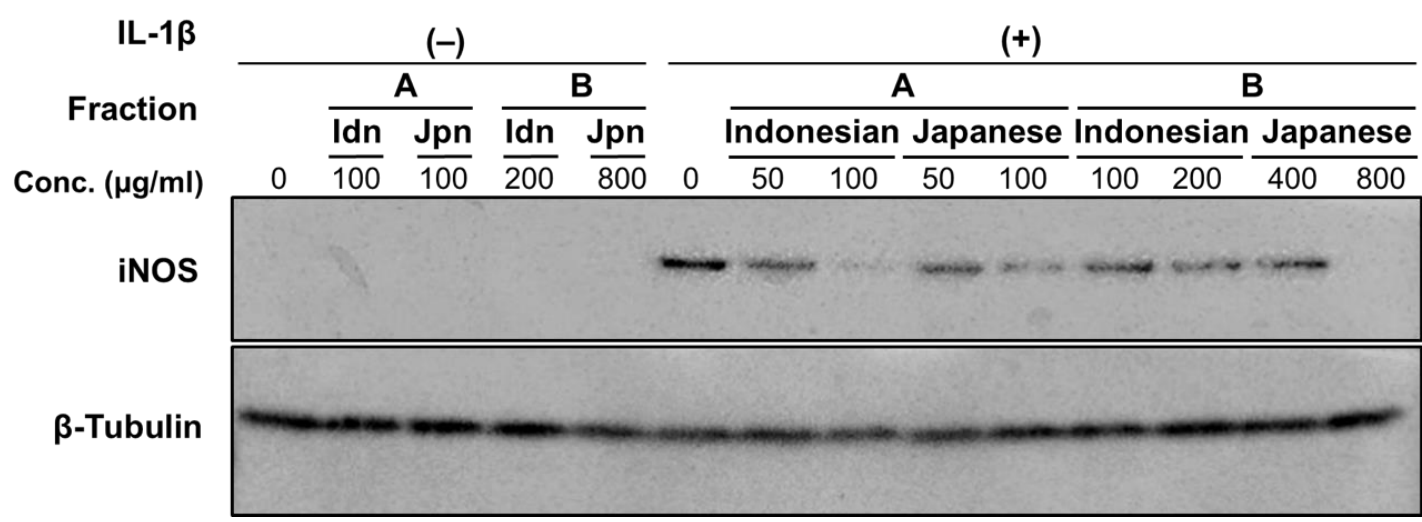

Figure 5. Fractions A and B of Indonesian and Japanese bitter melon extracts (BMEs) suppress iNOS protein expression in hepatocytes. The effects of fractions A and B of Indonesian and Japanese BMEs on the induction of iNOS protein. The hepatocytes were treated with IL- $1 \beta$ and/or Indonesian and Japanese BMEs for $8 \mathrm{~h}$ at $37^{\circ} \mathrm{C}$. The cell extracts from the hepatocytes were resolved using SDSPAGE and detected with anti-iNOS or anti- $\beta$-tubulin antibodies. 
Decrease in iNOS gene expression caused by fraction A of Indonesian and Japanese BMEs Quantitative RT-PCR was performed to examine whether fraction A of Indonesian and Japanese BMEs affected the expression of iNOS mRNA. Fraction A of BMEs suppressed the expression of iNOS mRNA in the hepatocytes in a dose-dependent manner (Figure 5A). Because the asRNA transcribed from the $i N O S$ gene interacts with and stabilizes the iNOS mRNA [21], the expression of iNOS asRNA was estimated. Fraction A significantly decreased the levels of iNOS asRNA in the presence of IL-1 $\beta$ (Figure 5B). These results suggest that fraction A of both BMEs may decrease the expression of iNOS protein by reducing the levels of iNOS mRNA and iNOS asRNA.
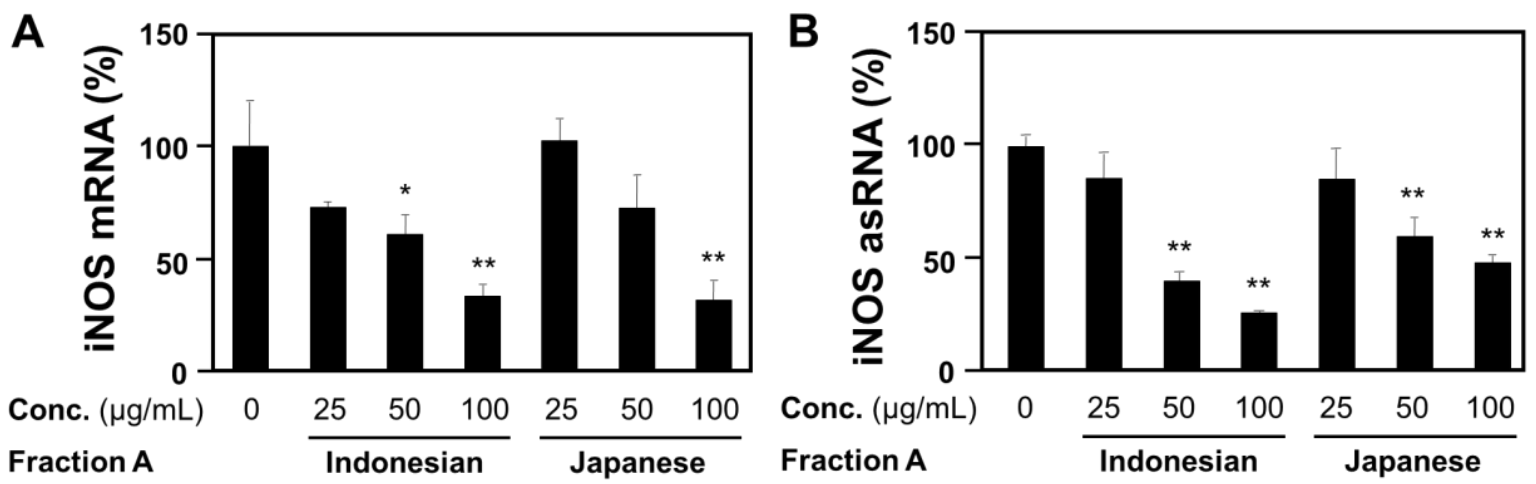

Figure 6. Fraction A of Indonesian and Japanese bitter melon extracts (BMEs) suppresses iNOS gene expression in hepatocytes. The effects of fraction A from Indonesian and Japanese BMEs on levels of iNOS mRNA (A) and iNOS asRNA (B). The hepatocytes were treated with IL-1 $\beta$ and/or fraction A of Indonesian and Japanese BMEs for $4 \mathrm{~h}$, and total cellular RNA was analyzed using quantitative RT-PCR to estimate the levels of iNOS mRNA and asRNA. These levels were measured in triplicate (mean $\pm \mathrm{SD}$ ) and normalized to elongation factor $1 \alpha(\mathrm{EF}) \mathrm{mRNA}$ (internal control). The values in the presence of IL- $1 \beta$ alone were set at $100 \%{ }^{*} P<0.05$ and ${ }^{* *} P<0.01$ versus IL-1 $\beta$ alone.

\section{Suppression of the expression of pro-inflammatory genes by bitter melon fraction $A$}

The pro-inflammatory cytokines tumor necrosis factor (TNF)- $\alpha$ and IL-6 play key roles in inflammation, and chemokine $\mathrm{C}-\mathrm{C}$ motif ligands 20 (CCL20) and $\mathrm{C}-\mathrm{X}_{3}-\mathrm{C}$ motif ligand 1 (CX3CL1) are also involved in this process. The levels of these cytokine and chemokine mRNA levels were induced by IL-1 $\beta$ stimulation of rat hepatocytes [28]. Therefore, we examined whether fraction A of Indonesian and Japanese BMEs affects these mRNA levels in hepatocytes. When fraction A was added to the medium, the mRNA levels of these proinflammatory genes significantly decreased (Figure 6), suggesting that fraction A of Indonesian and Japanese BMEs suppresses the transcription of these mRNAs. Similar to the inhibition of $\mathrm{NO}$ production, the $\mathrm{IC}_{50}$ values for suppression of the mRNA induction were comparable (data 
not shown). These results indicate that fraction A of Indonesian and Japanese BMEs suppresses not only NO but also the cytokine/chemokine mRNA in a dose-dependent manner.
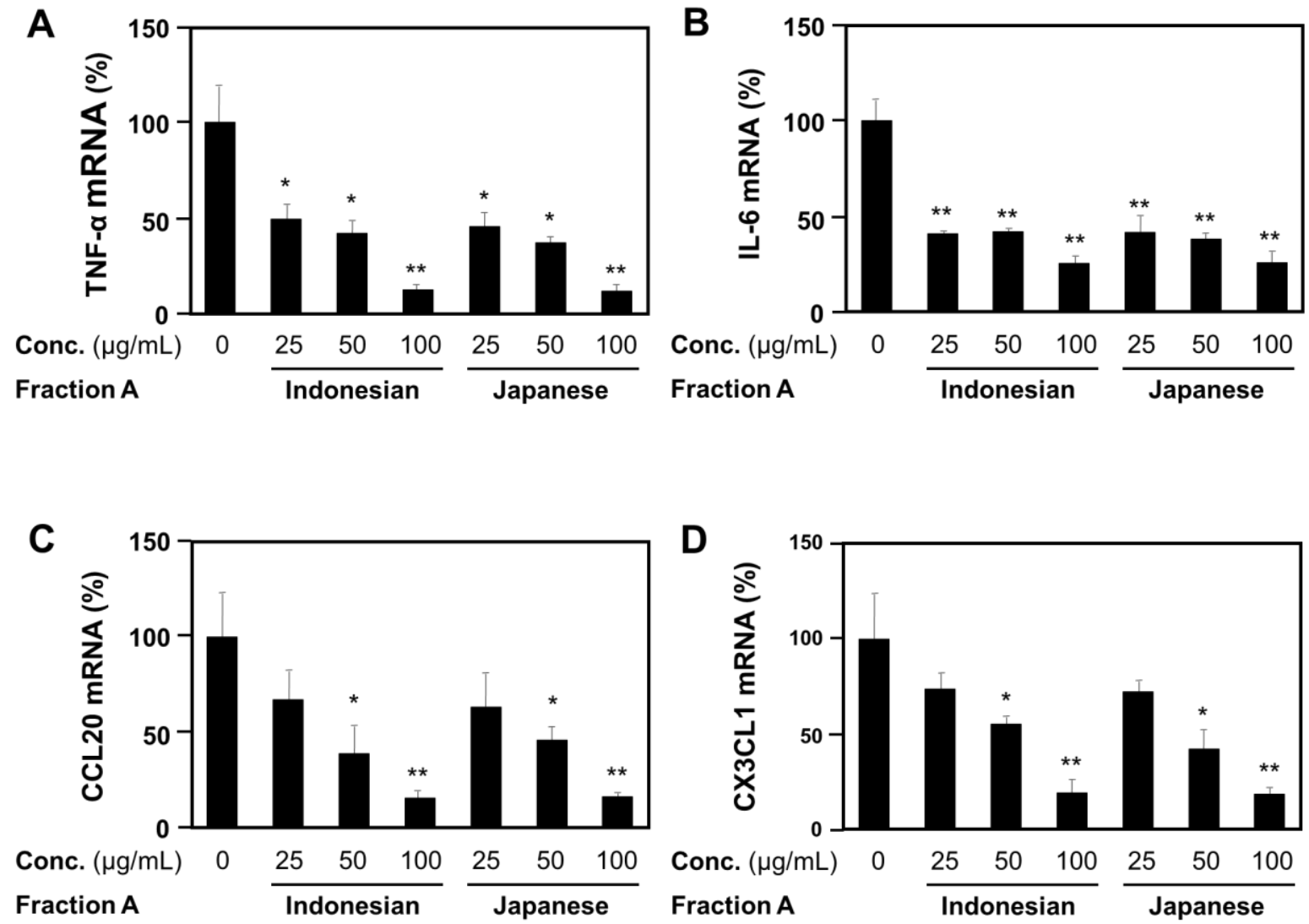

Figure 7. Fraction A of Indonesian and Japanese BMEs suppresses the expression of proinflammatory genes. The effects of fraction A from Indonesian and Japanese BMEs on the levels of tumor necrosis factor $\alpha$ (TNF- $\alpha$; A), interleukin 6 (IL-6; B), chemokine C-C motif ligand 20 (CCL20; C), and chemokine $\mathrm{C}-\mathrm{X}_{3}-\mathrm{C}$ motif ligand $1(\mathrm{CX} 3 \mathrm{CL} 1 ; \mathbf{D})$. The hepatocytes were treated with IL-1 $\beta$ and/or fraction A of Indonesian and Japanese BMEs for $4 \mathrm{~h}$, and total RNA was analyzed using quantitative RT-PCR. The mRNA levels were measured in triplicate (mean $\pm \mathrm{SD}$ ), and the obtained values were normalized to EF mRNA. The values in the presence of IL- $1 \beta$ alone were set at $100 \%$. ${ }^{*} P$ $<0.05$ and $*^{*} P<0.01$ versus IL- $1 \beta$ alone.

\section{DISCUSSION}

In this study, we demonstrated that both extracts from Indonesian and Japanese bitter melon suppressed IL-1 $\beta$-induced NO production in rat hepatocytes and that the ethyl acetate-soluble fraction A demonstrated the highest NO suppression activity. Fraction A of both BMEs revealed similar $\mathrm{IC}_{50}$ values (Table 2). Because NO is a sensitive marker for monitoring antiinflammatory effects [26, 29], our results suggest that bitter melon fraction A may have an antiinflammatory activity. In support of this finding, an aqueous extract of bitter melon was 
observed to reduce the serum NO concentration and protected the liver from damage induced by mitochondrial reactive oxygen species [30].

The results of the present study indicated that the extracts and fraction A of Indonesian and Japanese bitter melon extracts suppressed the expression of iNOS protein in IL- $1 \beta$-treated hepatocytes (Figures 3, 5). Furthermore, fraction A of both BMEs decreased the levels of iNOS mRNA (Figure 6). These results indicate that bitter melon fraction A likely inhibited the expression of the $i N O S$ gene at the transcriptional level or later.

Fraction A of both Indonesian and Japanese BMEs decreased the levels of mRNAs encoding pro-inflammatory cytokines (TNF- $\alpha$ and IL-6) and chemokines (CCL20 and CX3CL1) (Figure 7). TNF- $\alpha$ and IL-6 are the key players involved in chronic liver injury and inflammation $[31,32]$, and the expression of TNF- $\alpha$ mRNA is induced by IL- $1 \beta$ in rat hepatocytes [33]. Similar to Japanese herbal drugs and their constituents [34], bitter melon fraction A suppressed the expression of TNF- $\alpha$ and IL-6 mRNA. CCL20 was identified as liver and activation-regulated chemokine/macrophage inflammatory protein-3 $\alpha$ [35]. CX3CL1 increased with acute and chronic liver disease [36]. Therefore, the hydrophobic constituents of fraction A may exhibit anti-inflammatory effects by suppressing these pro-inflammatory cytokines and chemokines.

Bitter melon fruit contains low contents of many constituents [37]. Cucurbitane-type triterpenoids from bitter melon fruit are thought to possess anticancer, antioxidant, antidiabetic, and anti-hyperglycemic abilities [38-40]. Furthermore, steroidal glycosides from bitter melon fruit demonstrate potent antihyperglycemic and hypolipidemic activities [41]. Phenolic compounds and flavonoids from bitter melon fruit possess antioxidant, anti-inflammation, and immune-enhancing activities [42-44]. Our data suggest that hydrophobic constituents in fraction A (e.g., cucurbitane-type triterpenoids, flavonoids, and phenolic compounds) may be responsible for the observed anti-inflammatory effects. These hydrophobic constituents should be isolated to elucidate the anti-inflammatory effects of bitter melon.

In this study, we compared the pharmacological effects of bitter melon collected from two typical places of cultivation, Malang in Indonesia and Okinawa in Japan, where bitter melon is consumed as a traditional medicine and a vegetable. The $\mathrm{IC}_{50}$ value of Japanese BME was 1.99fold higher than that of Indonesian BME, while the $\mathrm{IC}_{50}$ values of fraction A of Japanese and Indonesian BMEs were similar (Table 2). Comparing these $\mathrm{IC}_{50}$ values, fractions $\mathrm{B}$ and $\mathrm{C}$ are suggested to contain different composition and content of the constituents responsible for the suppression of NO production. The constituents may differ depending on climatic conditions, soil nutritional conditions, and harvest time. Further analysis of the constituents will clarify the differences in the $\mathrm{IC}_{50}$ values and constituents between Indonesian and Japanese BMEs. 
Bitter melon fruit is usually cooked and eaten as a vegetable in Okinawa. The cooked bitter melon fruit is used as a healthy food. According to our results, searching literature up to date, there were no reports that health benefits are decreased by cooking procedures. We are currently purifying and analyzing the constituents in the bitter melon fruits. The effect by the cooking procedures on the pharmacological properties will be examined after the constituents are identified.

The recent clinical studies regarding the hypoglycemic effects of bitter melon are reviewed by Joseph and Jini [7]. However, the majority of these trials lacked proper controls or suffered from poor methodologies without baseline characterization [7]. Recently, Cortez-Navarrete et al. reported that administration of bitter melon fruit powder improved insulin secretion in type 2 diabetes mellitus patients [45]. More clinical trials are required to verify the pharmacological effects in the future.

\section{CONCLUSION}

Indonesian and Japanese bitter melon extracts exhibited similar activities for suppressing NO production and iNOS expression. The ethyl acetate-soluble fraction of Indonesian and Japanese BMEs have comparable activities for suppressing the expression of the iNOS and proinflammatory cytokine/chemokine genes. These data suggest that hydrophobic constituents in the ethyl acetate-soluble fraction of BMEs, such as cucurbitane-type triterpenoids, may be responsible for the anti-inflammatory effects of bitter melon.

Abbreviations: NO, nitric oxide; iNOS, inducible nitric oxide synthase; IL, interleukin; LDH, lactate dehydrogenase; IC 50 , half-maximal inhibitory concentration; SDS-PAGE, sodium dodecyl sulfate-polyacrylamide gel electrophoresis; RT, reverse transcription; PCR, polymerase chain reaction; asRNA, antisense transcript; BME, bitter melon extract; TNF- $\alpha$, tumor necrosis factor $\alpha$; CCL20, chemokine C-C motif ligand 20; CX3CL1, chemokine C-X ${ }_{3}$ $\mathrm{C}$ motif ligand $1 ; \mathrm{EF}$, elongation factor $1 \alpha$.

Acknowledgments: We thank Amino Up Co., Ltd. (Sapporo, Hokkaido, Japan) for freezedrying bitter melon samples and Ms. Noriko Kanazawa for her secretarial assistance.

Author contributions: DRD performed the experiments, data collection, statistical analysis, and drafted the manuscript as a graduate student. T. Okuyama and T. Okumura provided hepatocytes and advice regarding the experiments. MN and YI participated in the design of the study, supervised the study, and provided oversight in the drafting of the manuscript. 
Funding: This work was supported in part by the Asia-Japan Research Institute of Ritsumeikan Asia-Japan Research Organization, Ritsumeikan University (Ibaraki, Osaka, Japan).

\section{REFERENCES}

1. Harinantenaina L, Tanaka M, Takaoka S, Oda M, Mogami O, Uchida M, Asakawa Y: Momordica charantia constituents and antidiabetic screening of the isolated major compounds. Chem Pharm Bull 2006, 54: 1017-1021.

2. Pitipanapong J, Chitprasert S, Goto M, Jiratchariyakul W, Sasaki M, Shotipruk A: New approach for extraction of charantin from Momordica charantia with pressurized liquid extraction. Sep Purif Technol 2007, 52: 416-422.

3. Chen JC, Liu WQ, Lu L, Qiu MH, Zheng YT, Yang LM, Zhang XM, et al.: Kuguacins F-S, cucurbitane triterpenoids from Momordica charantia. Phytochemistry 2009, 70: 133-140.

4. Nakamura S, Murakami T, Nakamura J, Kobayashi H, Matsuda H, Yoshikawa M: Structures of new cucurbitane-type triterpenes and glycosides, karavilagenins and karavilosides, from the dried fruit of Momordica charantia L. in Sri Lanka. Chem Pharm Bull 2006, 54: 1545-1550.

5. Kubola J, Siriamornpun S: Phenolic contents and antioxidant activities of bitter gourd (Momordica charantia L.) leaf, stem and fruit fraction extracts in vitro. Food Chem 2008, 110: 881-890.

6. Horax R, Hettiarachchy N, Islam S: Total phenolic contents and phenolic acid constituents in 4 varieties of bitter melons (Momordica charantia) and antioxidant activities of their extracts. J Food Sci 2005, 70: C275-C280.

7. Horax R, Hettiarachchy N, Chen P: Extraction, quantification, and antioxidant activities of phenolics from pericarp and seeds of bitter melons (Momordica charantia) harvested at three maturity stages (immature, mature, and ripe). J Agric Food Chem 2010, 58 : $4428-4433$.

8. Nguyen XN, Phan VK, Chau VM, Ninh KB, Nguyen XC, Le MH, Bui HT, et al.: Cucurbitane-type triterpene glycosides from the fruits of Momordica charantia. Magn Reson Chem 2010, 48: 392-396.

9. Murakami T, Emoto A, Matsuda H, Yoshikawa M: Structures of new cucurbitane-type triterpene glycosides, goyaglycosides-a, -b, -c, -d, -e, -f, -g, and -h, and new oleananetype triterpene saponins, goyasaponins I, II, and III, from the fresh fruit of Japanese Momordica charantia L. Chem Pharm Bull 2001, 49: 54-63.

10. Shih CC, Lin CH, Lin WL: Effects of Momordica charantia on insulin resistance and visceral obesity in mice on high-fat diet. Diabetes Res Clin Pract 2008, 81: 134-143. 
11. Bano F, Akthar N, Naz H: Effect of the aqueous extracts of Momordica charantia on body weight of rats. Aust J Basic \& Appl Sci 2011, 7: 1-5.

12. Jayasooriya AP, Sakono M, Yukizaki C, Kawano M, Yamamoto K, Fukuda N: Effects of Momordica charantia powder on serum glucose levels and various lipid parameters in rats fed with cholesterol-free and cholesterol-enriched diets. J Ethnopharmacol 2011, 72: 331-336.

13. Tenmozhi AJ, Subramanian P: Antioxidant potential of Momordica charantia in ammonium chloride-induced hyperammonemic rats. J Evid Based Complementary Altern Med 2011: 1-8.

14. Zahra K, Malik MA, Mughal MS, Arshad M, Sohail MI: Hepatoprotective role of extracts of Momordica charantia L. in acetaminophen-induced toxicity in rabbits. J Anim Plant Sci 2012, 22: 273-277.

15. Sridhar MG, Vinayagamoorthi R, Suyambunathan VA, Bobby Z, Selvaraj N: Bitter gourd (Momordica charantia) improves insulin sensitivity by increasing skeletal muscle insulin-stimulated IRS-1 tyrosine phosphorylation in high-fat fed rats. Br J Nutr 2008, 99: 806-812.

16. Chaturvedi P: Antidiabetic potentials of Momordica charantia: multiple mechanisms behind the effects. J Med Food 2012, 15: 101-107.

17. Joseph B, Jini D: Antidiabetic effects of Momordica charantia (bitter melon) and its medicinal potency. Asian Pac J Trop Dis 2013, 3: 93-102.

18. Coleman JW: Nitric oxide in immunity and inflammation. Int Immunopharmacol 2001, 1: 1397-1406.

19. Colasanti M, Suzuki H: The dual personality of NO. Trends Pharmacol Sci 2000, 21: 249-252.

20. Aktan F: iNOS-mediated nitric oxide production and its regulation. Life Sci 2004, 75: 639-653.

21. Matsui K, Nishizawa M, Ozaki T, Kimura T, Hashimoto I, Yamada M, Kaibori M, et al.: Natural antisense transcript stabilizes inducible nitric oxide synthase messenger RNA in rat hepatocytes. Hepatology 2008, 47: 686-697.

22. Kitade H, Sakitani K, Inoue K, Masu Y, Kawada N, Hiramatsu Y, Kamiyama Y, et al.: Interleukin- $1 \beta$ markedly stimulates nitric oxide formation in the absence of other cytokines or lipopolysaccharide in primary cultured rat hepatocytes but not in Kupffer cells. Hepatology 1996, 23: 797-802

23. Ohno N, Yoshigai E, Okuyama T, Yamamoto Y, Okumura T, Sato K, Ikeya Y, et al.: Chlorogenic acid from the Japanese herbal medicine Kinginka (Flos Lonicerae japonicae) suppresses the expression of inducible nitric oxide synthase in rat hepatocytes. HOAJ Biol 2012, 1: 2. DOI: https://doi.org/10.7243/2050-0874-1-2. 
24. Kanemaki T, Kitade H, Hiramatsu Y, Kamiyama Y, Okumura T: Stimulation of glycogen degradation by prostaglandin $\mathrm{E}_{2}$ in primary cultured rat hepatocytes. Prostaglandins 1993, 45: 459-474.

25. Green LC, Wagner DA, Glogowski J, Skipper PL, Wishnok JS, Tannenbaum SR: Analysis of nitrate, nitrite, and $\left[{ }^{15} \mathrm{~N}\right]$ nitrate in biological fluids. Anal Biochem 1982, 126: $131-138$.

26. Inaba H, Yoshigai E, Okuyama T, Murakoshi M, Sugiyama K, Nishino H, Nishizawa M: Antipyretic analgesic drugs have different mechanisms for regulation of the expression of inducible nitric oxide synthase in hepatocytes and macrophages. Nitric Oxide 2015, 44: 61-70.

27. Nakanishi H, Kaibori M, Teshima S, Yoshida H, Kwon AH, Kamiyama Y, Nishizawa M, et al.: Pirfenidone inhibits the induction of iNOS stimulated by interleukin- $1 \beta$ at a step of NF-кB DNA binding in hepatocytes. J Hepatol 2004, 41: 730-736.

28. Takimoto Y, Qian HY, Yoshigai E, Okumura T, Ikeya Y, Nishizawa M. Gomisin N: in the herbal drug gomishi (Schisandra chinensis) suppresses inducible nitric oxide

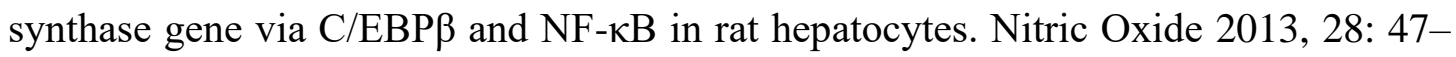
56.

29. Matsuura T, Kaibori M, Araki Y, Matsumiya M, Yamamoto Y, Ikeya Y, Nishizawa M, et al.: Japanese herbal medicine, inchinkoto inhibits inducible nitric oxide synthase induction in interleukin-1 $\beta$-stimulated hepatocytes. Hepatol Res 2012, 42: 76-90.

30. Deng Y, Tang Q, Zhang Y, Zhang R, Wei Z, Tang X, Zhang M: Protective effect of Momordica charantia water extract against liver injury in restraint-stressed mice and the underlying mechanism. Food Nutr Res 2017, 61: 1-11.

31. Kaibori M, Okumura T, Sato K, Nishizawa M, Kon M: Inducible nitric oxide synthase expression in liver injury: liver protective effects on primary rat hepatocytes. Inflamm Allergy Drug Targets 2015, 14: 77-83.

32. Kopf M, Baumann H, Freer G, Freudenberg M, Lamers M, Kishimoto T, Zinkernagel $\mathrm{R}$, et al.: Impaired immune and acute-phase responses in interleukin-6-deficient mice. Nature 1994, 368:339-342.

33. Yoshigai E, Hara T, Inaba H, Hashimoto I, Tanaka Y, Kaibori M, Kimura T, et al.: Interleukin- $1 \beta$ induces tumor necrosis factor- $\alpha$ secretion from rat hepatocytes. Hepatol Res 2014, 44: 571-583.

34. Tanemoto R, Okuyama T, Matsuo H, Okumura T, Ikeya Y, Nishizawa M: The constituents of licorice (Glycyrrhiza uralensis) differentially suppress nitric oxide production in interleukin-1 $\beta$-treated hepatocytes. Biochem Biophys Rep 2015, 2:153159

35. Affo S, Morales-Ibanez O, Rodrigo-Torres D, Altamirano J, Blaya D, Dapito DH, Millán C, et al.: CCL20 mediates lipopolysaccharide induced liver injury and is a 
potential driver of inflammation and fibrosis in alcoholic hepatitis. Gut 2014, 63: 17821792.

36. Bourd-Boittin K, Basset L, Bonnier D, L'helgoualc'h A, Samson M, Théret N: CX3CL1/fractalkine shedding by human hepatic stellate cells: contribution to chronic inflammation in the liver. J Cell Mol Med 2009, 13: 1526-1535.

37. Jia S, Shen M, Zhang F, Xie J: Recent advances in Momordica charantia: functional components and biological activities. Int J Mol Sci 2017, 18: 1-25.

38. Agrawal RC, Beohar T: Chemopreventive and anticarcinogenic effects of Momordica charantia extract. Asian Pac J Cancer Prev 2010, 11: 371-375.

39. Liu CH, Yen MH, Tsang SF, Gan KH, Hsu HY, Lin CN: Antioxidant triterpenoids from the stems of Momordica charantia. Food Chem 2010, 118: 751-756.

40. Chou CH, Liao MH, Chen TM, Cheng CH, Anggriani R, Tsai CP, Tseng HI, et al.: Bitter melon triterpenes work as insulin sensitizers and insulin substitutes in insulinresistant cells. J Funct Foods 2015, 13: 214-224.

41. Hsiao PC, Liaw CC, Hwang SY, Cheng HL, Zhang LJ, Shen CC, Hsu FL, et al.: Antiproliferative and hypoglycemic cucurbitane-type glycosides from the fruits of Momordica charantia. J Agric Food Chem 2013, 61: 2979-2986.

42. Anila L, Vijayalakshmi NR: Beneficial effects of flavonoids from Sesamum indicum, Emblica officinalis and Momordica charantia. Phytother Res 2000, 14: 592-595.

43. Qader SW, Abdulla MA, Chua LS, Najim N, Zain MM, Hamdan, S: Antioxidant, total phenolic content and cytotoxicity evaluation of selected Malaysian plants. Molecules 2011, 16: 3433-3443.

44. Bajpai M, Pande A, Tewari SK, Prakash D: Phenolic contents and antioxidant activity of some food and medicinal plants. Int J Food Sci Nutr 2005, 56: 287-291.

45. Cortez-Navarrete M, Martínez-Abundis E, Pérez-Rubio KG, González-Ortiz M, Méndez-Del Villar M: Momordica charantia administration improves insulin secretion in type 2 diabetes mellitus. J Med Food 2018, 21: 672-677. 